Available online at GSC Online Press Directory

GSC Biological and Pharmaceutical Sciences

e-ISSN: 2581-3250, CODEN (USA): GBPSC2

(RESEARCH ARTICLE)

\title{
Effects of trypanosomosis on hemogram and some biochemical parameters of guinea pigs experimentally infected with Trypanosoma brucei brucei in Maiduguri, Nigeria
}

\author{
Abdullahi A. M. ${ }^{1}$, Iliyasu D. ${ }^{2}$, Galadima H. B. ${ }^{3,}{ }^{*}$, Ibrahim U. I. ${ }^{4}$, Mbaya A. W. ${ }^{5}$ and Wiam I. ${ }^{6}$ \\ ${ }^{1}$ Veterinary Teaching Hospital, Faculty of Veterinary Medicine University of Maiduguri, Nigeria. \\ ${ }^{2}$ Department of Theriogenology, Faculty of Veterinary Medicine, University of Maiduguri, Nigeria. \\ ${ }^{3}$ Department of Animal Health and Production, College of Agriculture, Gujba, Yobe state, Nigeria. \\ ${ }^{4}$ Department of veterinary medicine, Faculty of Veterinary Medicine, University of Maiduguri, Nigeria. \\ ${ }^{5}$ Department of Veterinary Parasitology and Entomology, Faculty of Veterinary Medicine, University of Maiduguri, \\ Nigeria. \\ ${ }^{6}$ Department of Veterinary Pathology, Faculty of Veterinary Medicine, University of Maiduguri, Nigeria.
}

Publication history: Received on 15 January 2019; revised on 25 March 2019; accepted on 02 April 2019

Article DOI: https://doi.org/10.30574/gscbps.2019.7.1.0007

\begin{abstract}
The study was designed to evaluate the effect of tryponosomosis on hemogram and some biochemical parameters of guinea pigs. Guinea pigs of both sexes weighing (5-10kg) were divided into six groups (A, B, C, D, E and F) with five guinea pigs in each group. At day zero, to establish the baseline data, all the animals in each of the six groups were bled for haematology and serum biochemistry and also clinical parameters (rectal temperature, respiratory rate, pulse rate and heart beats) were recorded while general body condition and physical signs were also evaluated. Groups A, B and C were intraperitoneally (IP) inoculated with $1 \times 10^{6}$ dose of Trypanosoma brucei brucei contained in $0.5 \mathrm{ml}$ of blood. Thereafter, blood samples were collected every other four (4) days for evaluation of hematology and serum electrolytes through the experimental period. Group D, E and F was uninfected control. All the infected groups (A, B, and C) had a pre-patent period of 16 days with similar levels of parasitaemia of $45.7 \pm 3.38$ across the groups. The observed clinical signs among the infected groups (A, B and C) were pyrexia, pale feet, snout, pinnae and mucous membrane, anaemia, dullness, emaciation and loss of weight. In group A, a mean parasitaemia of $2.8 \pm 0.84$ occurred by day 16 post-infection post infection which continued to rise significantly without abating $(p<0.05)$ to a peak count of $120.2 \pm 5.48$ by day 40 post infection. Similar findings was noticed across the groups. In groups D, E and F, their respective pre-infection RBC values of $6.20 \pm 1.24,6.24 \pm 1.24$ and $6.18 \pm 1.24$ remained fairly constant $(p>0.05)$. Dose of Veriben ${ }^{\circledR}$ administered at the dose rate of $7.0 \mathrm{mg} / \mathrm{kg}$ and $3.5 \mathrm{mg} / \mathrm{kg}$ have the abilities of curbing the state of anaemia, immunosuppression, and serum electrolytes levels in trypanosome-infected guinea pigs placed on a dose dependent manner.
\end{abstract}

Keywords: Hemogram; Biochemical parameters; Trypanosomosis; Guinea pigs

\section{Introduction}

Trypanosomosis is one of the most important zoonotic disease commonly found in Africa regions and South America [1]. African trypanosomosis is caused by a protozoan parasite belonging to the genus Trypanosoma, and is transmitted by tsetse flies to the final host. The disease is characterised by high morbidity and mortality of infected livestock. Animal trypanosomosis has been estimated to cost Africa about US\$ 4.5 billion per year [2]. Trypanosomosis affect almost all vertebrates particularly man and livestock. But wild animals such as Bovidae and suidae, act as asymptomatic carriers

\footnotetext{
${ }^{*}$ Corresponding author

E-mail address: haruna5539@yahoo.com
} 
[3]. Biological transmission (cyclic) of these parasites by tsetse fly (Glossina), is rampart in tsetse belt zone of Nigeria $[3,4]$. While arthropod vectors, haematophagus, of the family Tabanidae, Hippoboscidae, Stomoxynae Haematopota, lyperosia, and Chrysops species are responsible for the mechanical transmission of the parasite in the tropics $[5,6]$. Tsetse flies are efficient transmitters of trypanosomes especially Trypanosoma vivax which develop in their mouth [7]. Transplacental transmission of trypanosomes has been reported in cattle [8]. Trypanosoma vivax, T. congolense and $T$. brucei have been reported to cause Nagana in cattle, while T. evansi caused surra in camels (Camelus dromedarieus) [9]. Trypanosoma brucei gambiense and T. brucei rhodeseinse are responsible for human sleeping sickness in East and West Africa countries respectively, while T. cruzi transmitted by triatomid bugs (Triatonia Magista) is responsible for causing chagas disease in humans in South America [10]. The trypanosomes group of T. brucei (T. brucei, T. b. gambiense, T. $b$. rhodensiense and T. evansi) are more of tissue invading (humoral) parasites whereas, T. congolense, T. vivax and T. cruzi are restricted as hemoparasites (blood circulation parasites) or (haemic) [11, 12]. Animal trypanosomosis is lethal if left untreated. It causes severe losses in livestock industries as a result of poor growth, weight loss, and low milk yield, poor capacity to work, infertility and abortion have been reported in low levels of infection [3]. Control of the disease therefore is significant through hematological and biochemical evaluation that can lead to a reliable diagnosis that can guarantee optimistic treatment that will restore production in endemic areas and also boost livestock production industries.

\section{Material and methods}

\subsection{Source of Trypanosoma brucei brucei}

The trypanosoma parasites used for the study was "Federe" strain of Trypanosoma brucei brucei, which was obtained from NITOR (Nigerian Institute of Trypanosome and Onchocerciasis) Kaduna State. Nigeria. The organism was isolated from an outbreak of bovine trypanosomosis in Nassarawa State of Nigeria. It was identified based on its morphology and negative blood inhibition and infectivity test and was stabilized by four passage in rats before storage in liquid nitrogen (LN). Four donor rats were used to multiply the parasites and transported by road from Kaduna to the Department of Veterinary Medicine, Faculty of Veterinary Medicine, University of Maiduguri, Borno State, Nigeria. The parasites were then maintained in Albino rats by serial passage until used.

\subsection{Experimental animals}

Total of Thirty (30) apparently healthy Guinea pigs of both sexes and of different ages were used in the study. The animals were purchased from breeders in Plateau State. On arrival, they were kept in clean and well ventilated cages in the Large Animal Veterinary Clinic, Faculty of Veterinary Medicine, university of Maiduguri, Nigeria. They were routinely screened for ecto, haemo and endo parasites using standard methods [5]. The Guinea pigs were housed in a suitable locally made wire mesh cages with sawdust as bedding, fed with varieties of vegetables and commercial growers feed (Vital Feeds, PLC, Nigeria), and water provided ad libitum. They were allowed to acclimatize to laboratory condition for two weeks prior to commencement of the experiment. The experimental procedure was in accordance with regulations of the Ethical Committee of the Faculty of Veterinary Medicine, University of Maiduguri.

\subsection{Experimental infection}

Four (4) adult albino rats were used as donors of T. brucei brucei, the rats were purchased from NITOR, Kaduna State. They were screened for internal and external parasites using standard method as described by [5]. They were inoculated intra peritoneally with $0.5 \mathrm{ml}$ of $T$. brucei brucei parasiteamic blood with multiple parasites. At 4 days post inoculation, parasiteamia was established and became obvious. The donor rats were bled via the tail vein into a petri dish, the blood was diluted with phosphate buffered saline glucose (PBSG) (pH 7.4). Each Guinea pig in groups A, B and $\mathrm{C}$ were inoculated intraperitoneally with $0.5 \mathrm{ml}$ of blood containing $1.0 \times 10^{6}$ Trypanosoma brucei brucei as quantified using serial dilution as reported by Herbert and Lumsden [13].

\subsection{Experimental design}

Thirty Guinea pigs were randomly divided into six groups with five Guinea pigs in group (A, B, C, D, E and F). At day zero, all the animals were bled for haematology and serum biochemistry to establish a baseline data. Thereafter, physical condition and clinical parameters of all the animals were evaluated (rectal temperature, respiratory rate, pulse rate and heart beats) and body weights respectively. Groups A, B and C were inoculated with $0.5 \mathrm{ml}$ of blood containing $1.0 \times 10^{6}$ Trypanosoma brucei brucei intraperitoneally (IP). Blood sample were collected for haematology and serum electrolytes profiles at interval of 4 days from day zero until the end of the experiment. Group A was infected with 0.5 $\mathrm{ml}$ of blood containing $1.0 \times 10^{6}$ Trypanosoma brucei brucei (untreated control), Group B was infected with $0.5 \mathrm{ml}$ of blood containing $1.0 \times 10^{6}$ Trypanosoma brucei brucei (treated with Diaminazene diaceturate Veriben ${ }^{\circledR}$ at day 28 post 
infection at the dose rate of $7.0 \mathrm{mg} / \mathrm{kg}$ body weight. Group C was infected with $0.5 \mathrm{ml}$ of blood containing $1.0 \times 10^{6}$ Trypanosoma brucei brucei (treated with Diaminazene diaceturate (Veriben ${ }^{\circledR}$ ) at day 28 post infection at the dose rate of $3.5 \mathrm{mg} / \mathrm{kg}$ body weight. While Group D and Group E were uninfected/untreated (control) and uninfected treated with diaminazene diaceturate (Verben ${ }^{\circledR}$ ) at day 28 (p.i) at the dose rate of $7.0 \mathrm{mg} / \mathrm{kg}$ body weight respectively. Group $\mathrm{F}$ was uninfected (treated with diaminazene diaceturate (Veriben ${ }^{\circledR}$ ) at day 28 post infection at the dose rate of $3.5 \mathrm{mg} / \mathrm{kg}$ body weight.

\subsection{Post infection evaluation of guinea pigs}

All the Guinea pigs were observed daily for the manifestation of clinical signs of trypanosomosis, which include morbidity and mortality. Meanwhile, detection of parasitaemia was done every 4 days post day zero and the degree of parasitaemia was projected by the rapid matching technique as described by Herbert and Lumsden [13].

\subsection{Blood collection}

Blood for haematological and serum electrolytes examination were aseptically collected at 4 days interval preliminary from day 0 to day 64 post infection. The Guinea pigs were bled using $2 \mathrm{ml}$ syringe through cardiac puncture $0.5 \mathrm{ml}$ and $1 \mathrm{ml}$ of the blood was transferred into tubes containing anticoagulants (EDTA) and plain for hematological indices and sera for biochemical profiles respectively. Hematological and biochemical parameters were determine as described Henry et al [14] and Tietz [15].

\subsection{Statistical analysis}

Data generated were expressed as mean \pm standard deviation (SD) using Two-way analysis of variance was used to compare the data between groups and value $\mathrm{p}<0.05$ was considered significant (Graph Pad. Instat, 2009).

\section{Results}

The prepatent period in both groups was the same form 4 - 8 days post infection. Following patency, parasitaemia fluctuated considerably in both groups with a higher recorded and least in group A and B respectively as presented in figure 1.
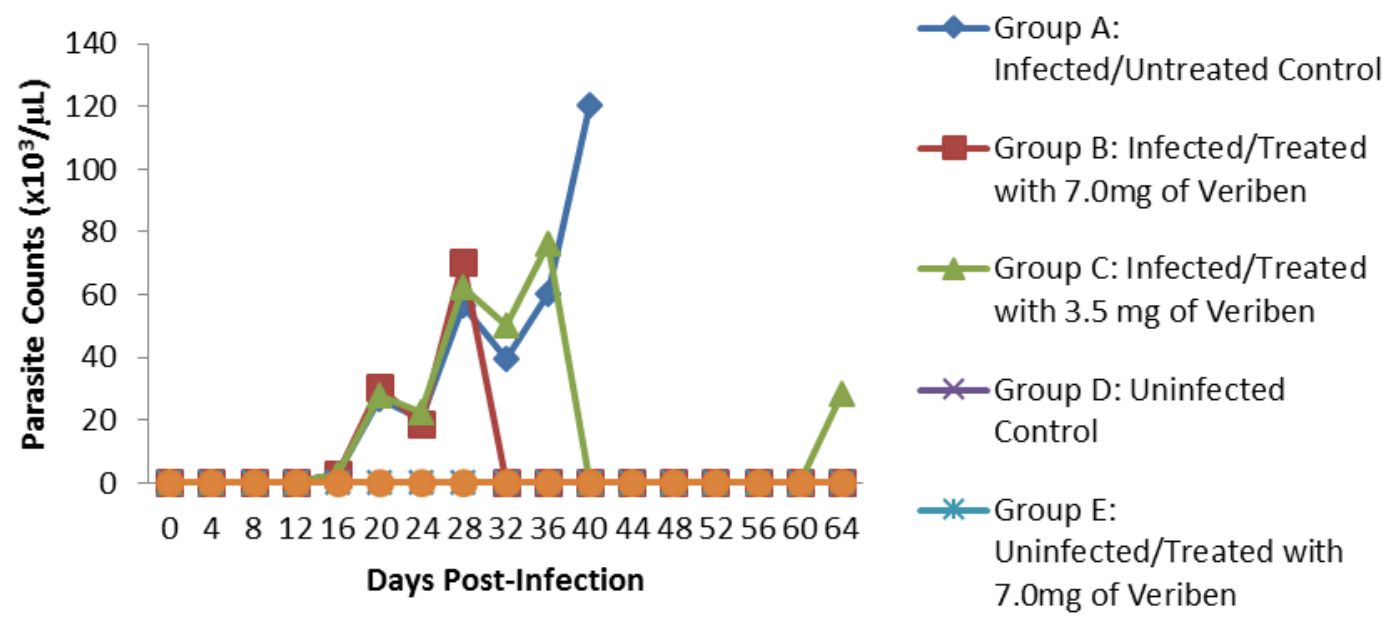

Figure 1 Effect of diminazene diaceturate (Veriben $®)$ on the mean parasite counts (x103/ $\mu \mathrm{L})$ of Guinea pigs (C. porcellus) experimentally infected with T. brucei brucei and their controls

There was a significant decrease in PCV values of both infected groups compared with their controls (Fig 2). The decline in PCV values began with the arrival of trypanosomes in circulation of all the infected groups with different degrees of anaemia as shown in figure 2. 


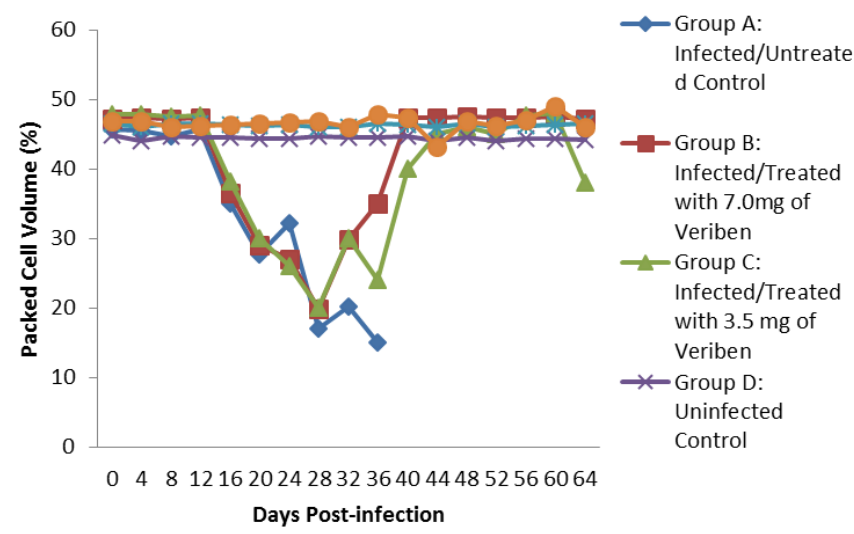

Figure 2 Effect of diminazene diaceturate $\left(\right.$ Veriben $\left.^{\circledR}\right)$ on the mean packed cell volume (\%) of Guinea pigs (C. porcellus) experimentally infected with T. brucei brucei and their controls

The value of RBC declined significantly $(\mathrm{p}<0.05)$ in all the infected groups following parasitaemia without reduction up to day 40 post infection in group A as presented in figure 3.
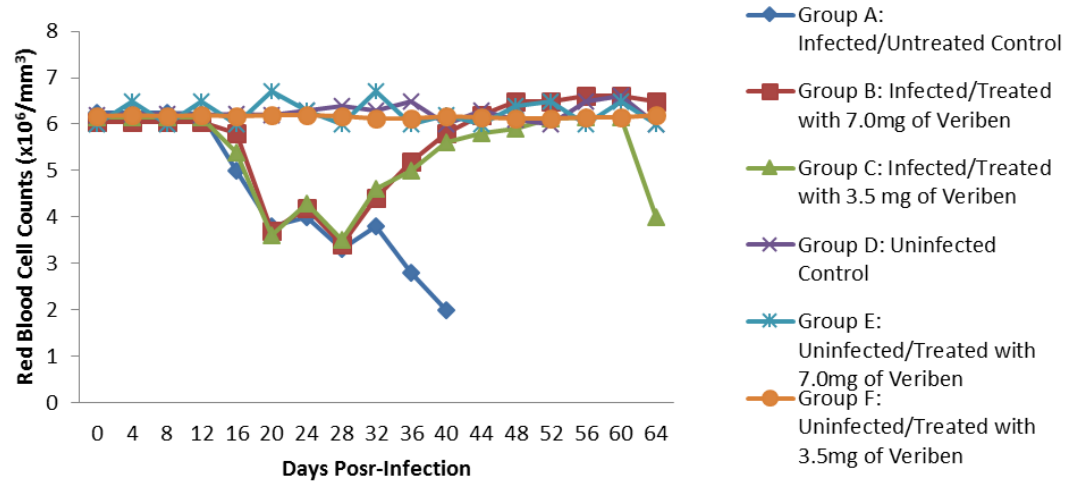

Figure 3 Effect of diminazene diaceturate (Veriben ${ }^{\circledR}$ ) on the mean red blood cell counts (x106/mm3) of Guinea pigs (C. porcellus) experimentally infected with T. brucei brucei and their controls

Group A, Hb value significantly decreased following parasitaemia hence, the Hb value continued to declined significantly $(\mathrm{p}<0.05)$ without abating up to day 40 post infection as documented in figure 4 .

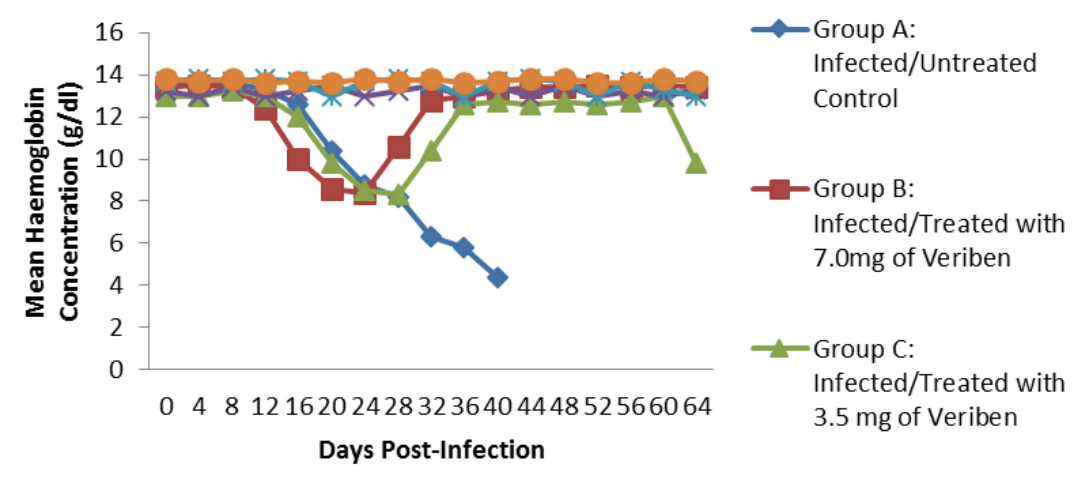

Figure 4 Effect of diminazene diaceturate (Veriben ${ }^{\circledR}$ ) on the mean haemoglobin concentration (g/dl) of Guinea pigs (C. porcellus) experimentally infected with T. brucei brucei and their controls

From day 16 (pi) when parasitaemia became patent in all the infected groups, the WBC value continuous to declined significantly particularly prominent in group A and B as shown in figure 5. 

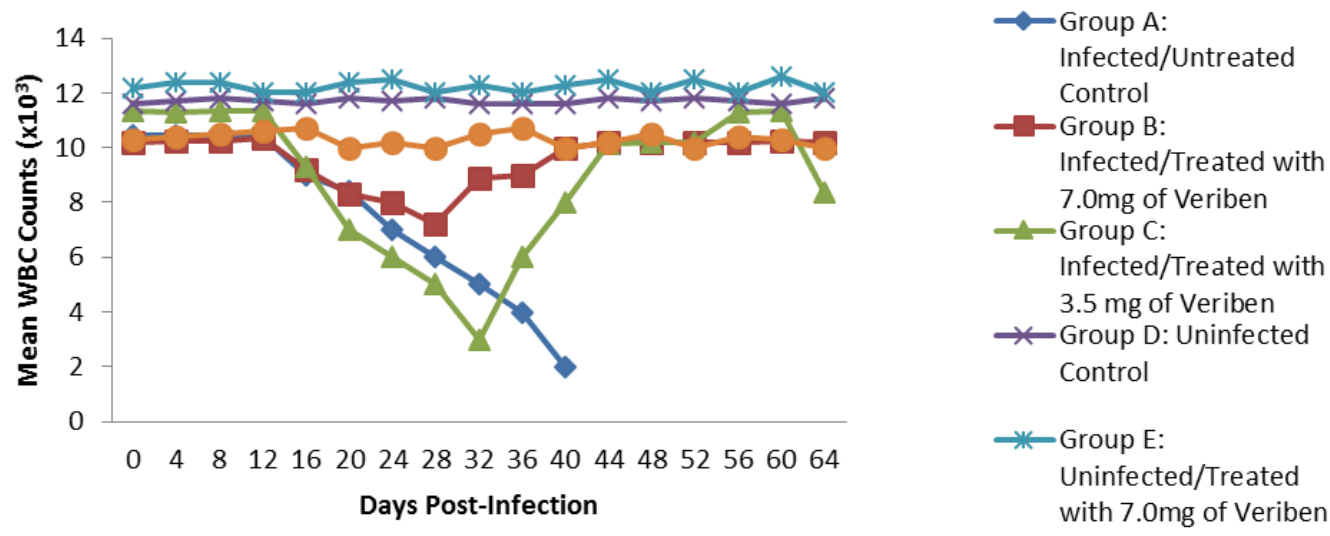

Figure 5 Effect of diminazene diaceturate $\left(\right.$ Veriben $\left.^{\circledR}\right)$ on the mean White Blood Cell counts $\left(\mathrm{x} 10^{3}\right)$ of Guinea pigs $(C$. porcellus) experimentally infected with T. brucei brucei and their controls

The differential leucocytes counts of all the infected groups declined following the establishment of parasitaemia by day 16 post infection, hence the value continue to declined significantly $(\mathrm{p}<0.05)$ in group $A, B$ and $C$ as indicated in figure 6, 7 and 9. While there was significant decreased in platelets count in all the infected groups following parasitaemia appearance in day 16 post infection in group A and B as shown in figure 8.
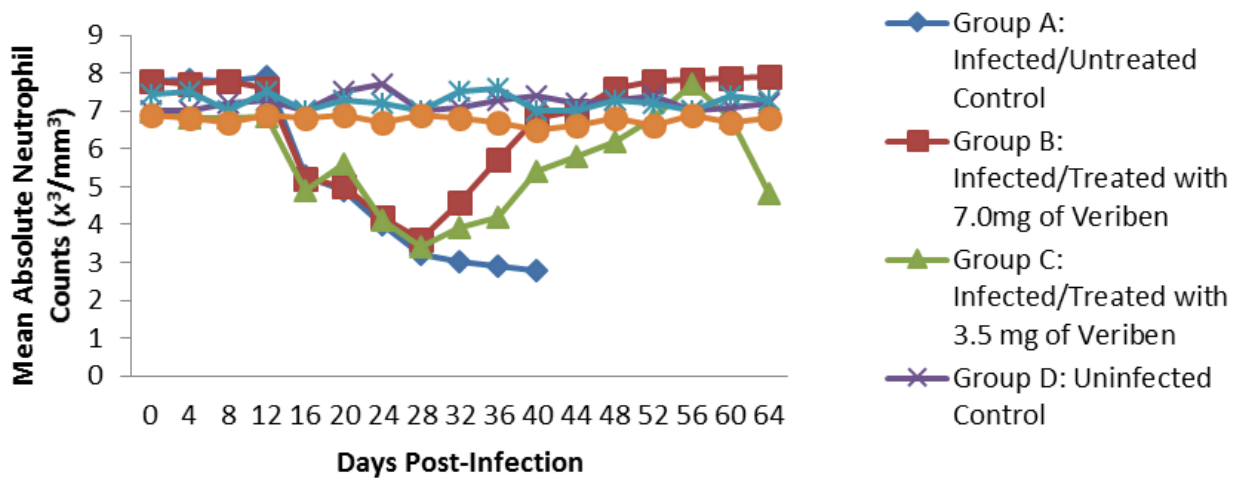

Figure 6 Effect of diminazene diaceturate (Veriben $\AA$ ) on the mean absolute neutrophil counts (x3/mm3) of Guinea pigs (C. porcellus) experimentally infected with T. brucei brucei and their controls
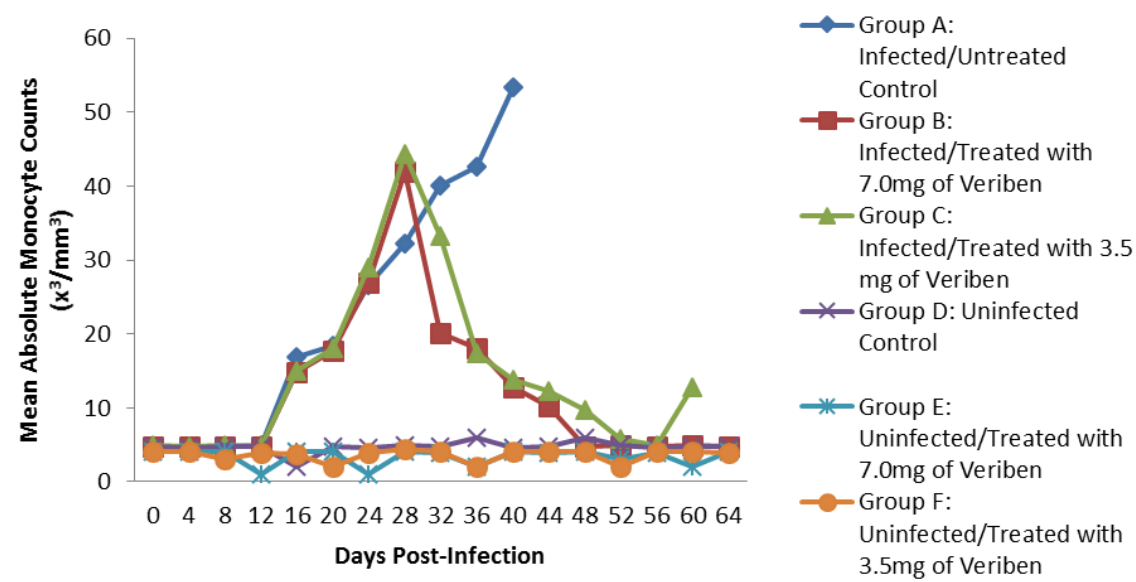

Figure 7 Effect of diminazene diaceturate (Veriben ${ }^{\circledR}$ ) on the mean absolute monocyte counts $\left(\mathrm{x}^{3} / \mathrm{mm}^{3}\right)$ of Guinea pigs (C. porcellus) experimentally infected with $T$. brucei brucei and their controls 

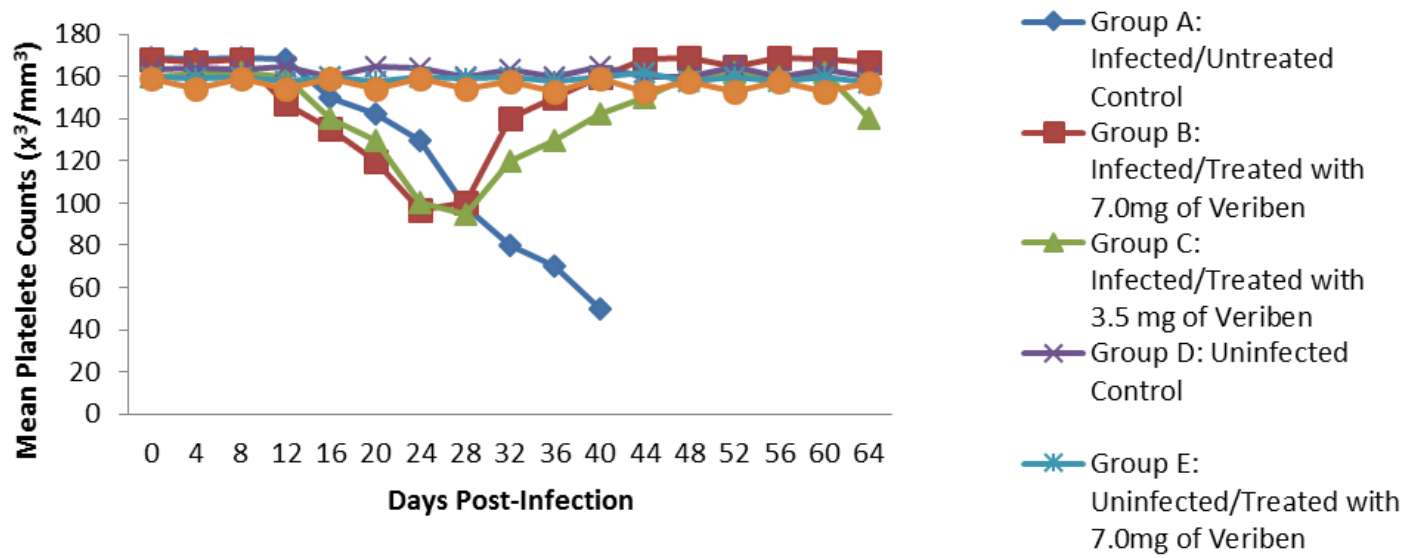

Figure 8 Effect of diminazene diaceturate (Veriben $\left.{ }^{\circledR}\right)$ on the mean platelete counts $\left(\mathrm{x}^{3} / \mathrm{mm}^{3}\right)$ of Guinea pigs $(C$. porcellus) experimentally infected with T. brucei brucei and their controls
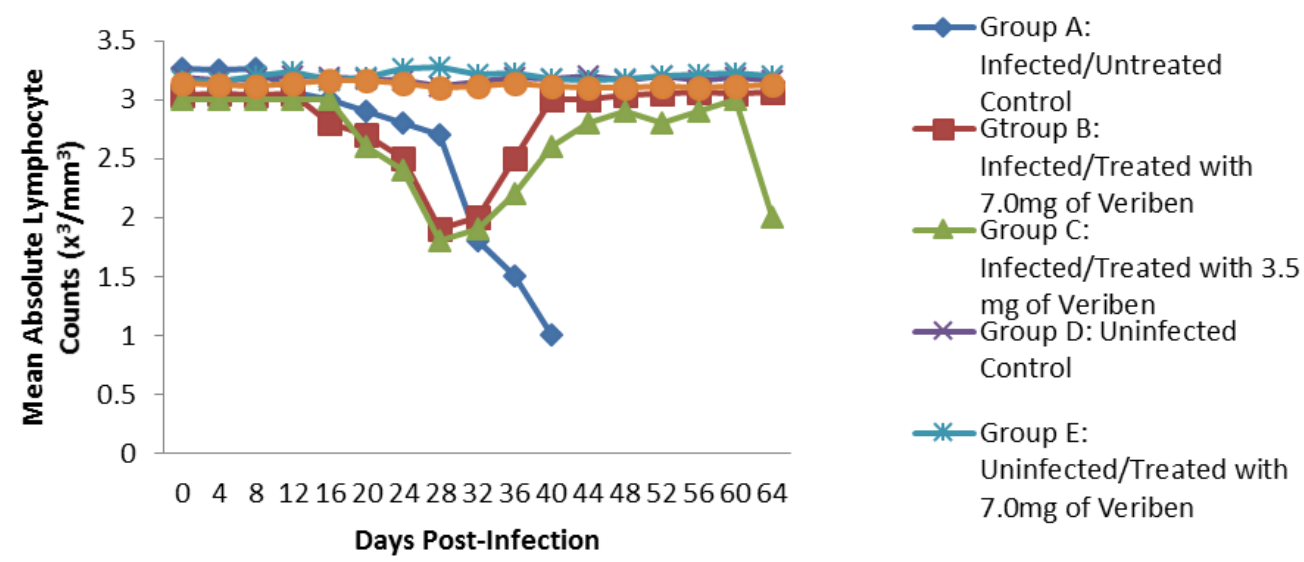

Figure 9 Effect of Diminazene diaceturate (Veriben $®)$ on the mean absolute lymphocyte counts (x3/mm3) of Guinea pigs (C. porcellus) experimentally infected with T. brucei brucei and their controls

In group $\mathrm{A}$, the values of MCV decreased significantly $(\mathrm{p}<0.05)$ following establishment of parasitaemia by day 16 post infection similar findings was observed on the mean corpuscular haemoglobin $\mathrm{MCH}$ of the Guinea pigs (C. porcellus) as presented in (Fig 10, 11 and 12).
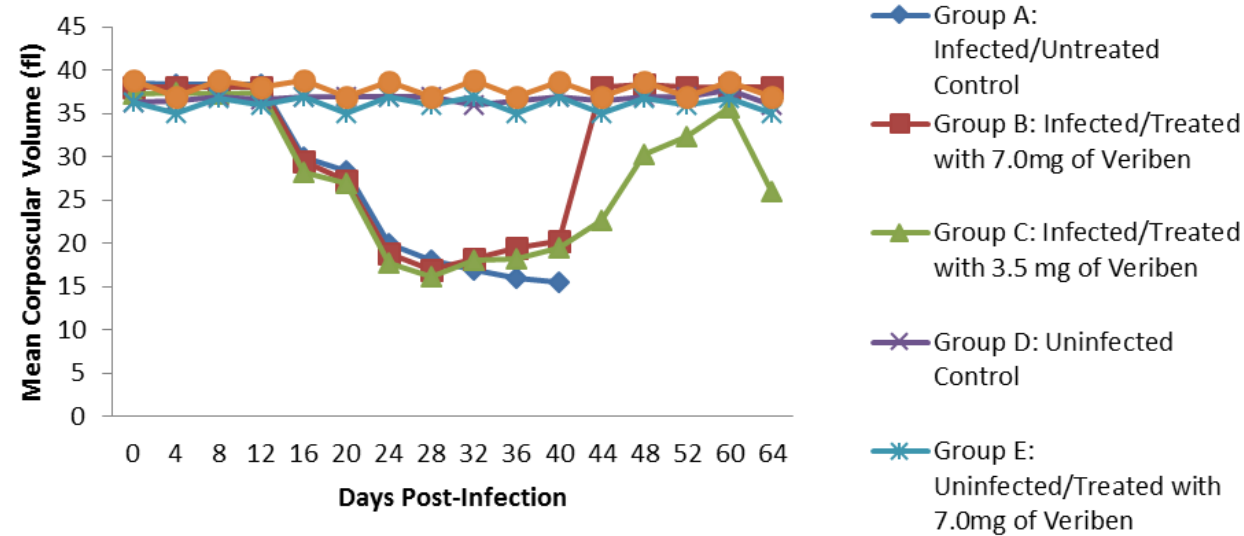

Figure 10 Effect of diminazene diaceturate (Veriben $\left.{ }^{\circledR}\right)$ on the mean corpuscular volume (fl) of Guinea pigs $(C$. porcellus) experimentally infected with T. brucei brucei and their controls 

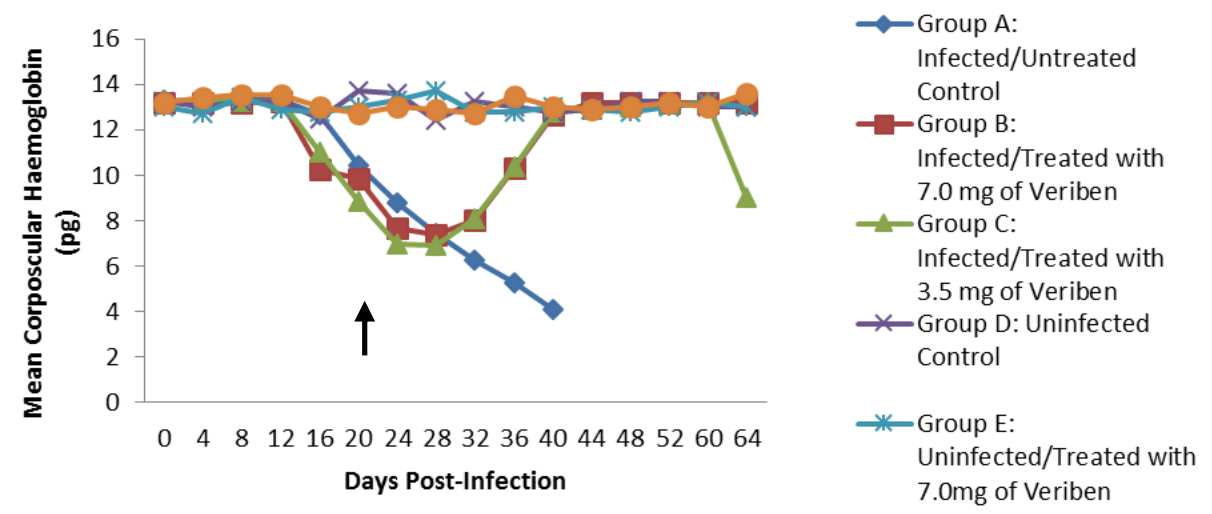

Figure 11 Effect of diminazene diaceturate (Veriben $\left.{ }^{\circledR}\right)$ on the mean corpuscular haemoglobin (pg) of Guinea pigs $(C$. porcellus) experimentally infected with T. brucei brucei and their controls
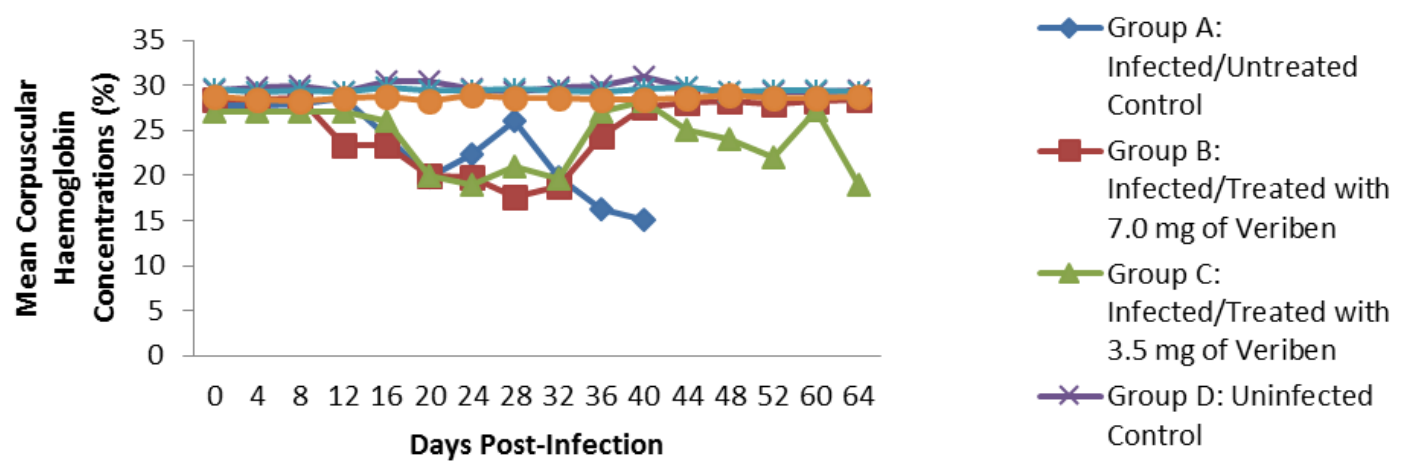

Figure 12 Effect of diminazenazene diaceturate (Veriben $®$ ) on the mean corpuscular haemoglobin concentration of Guinea pigs (C. porcellus) experimentally infected with T. brucei brucei and their controls

The mean chloride ion concentrations of the Guinea pigs (C. porcellus) continually decreased following establishment of parasitaemia by day 16 post infection in all the treated groups at different days, similar findings was noticed on the mean bicarbonate ion concentrations of the Guinea pigs (C. porcellus) at day 16 post infection and mean serum sodium levels of Guinea pigs ( $C$. porcellus) the serum sodium levels decreased significantly following establishment of parasitaemia by day 16 post infection in all the treated groups as show in (Fig 13,14 and 15).
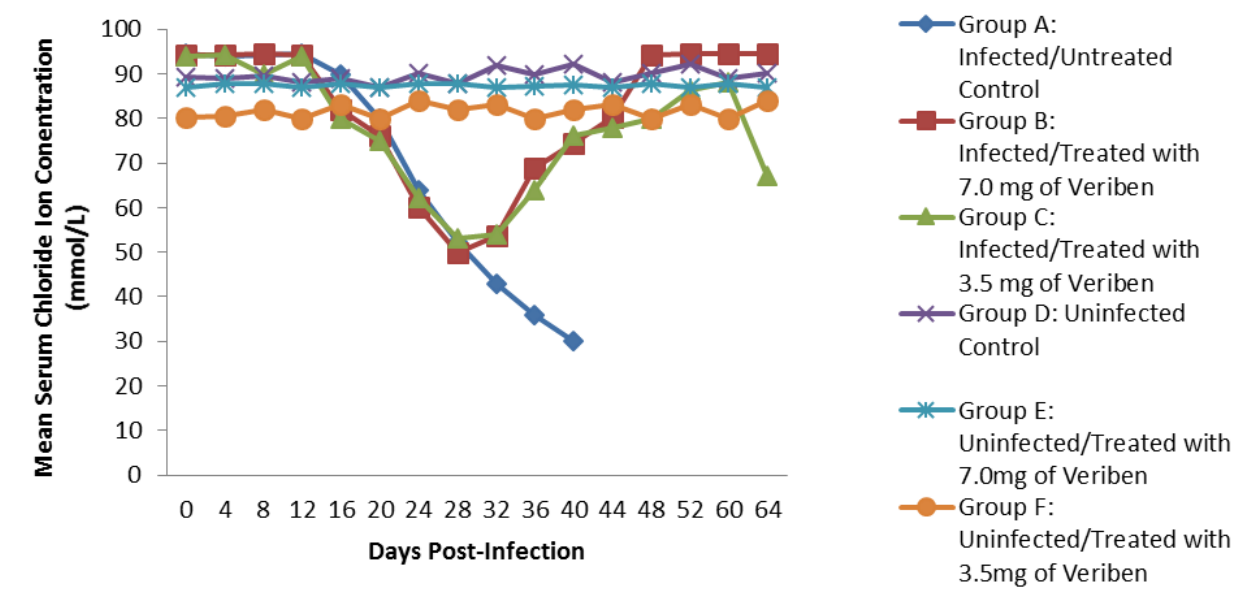

Figure 13 Effect of diminazene diaceturate (Veriben $®$ ) on the mean serum chloride ion concentration (mmol/L) of Guinea pigs (C. porcellus) experimentally infected with T. brucei brucei and their controls 

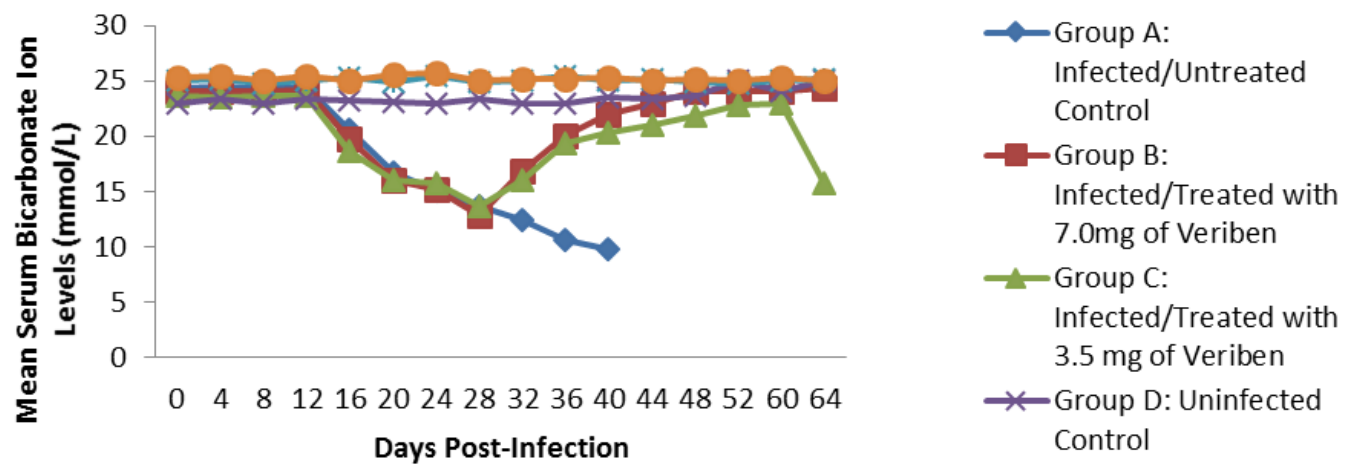

Figure 14 Effect of diminazene diaceturate (Veriben $($ ) $)$ on the mean serum bicarbonate ion levels (mmol/L) of Guinea pigs (C. porcellus) experimentally infected with T. brucei brucei and their controls
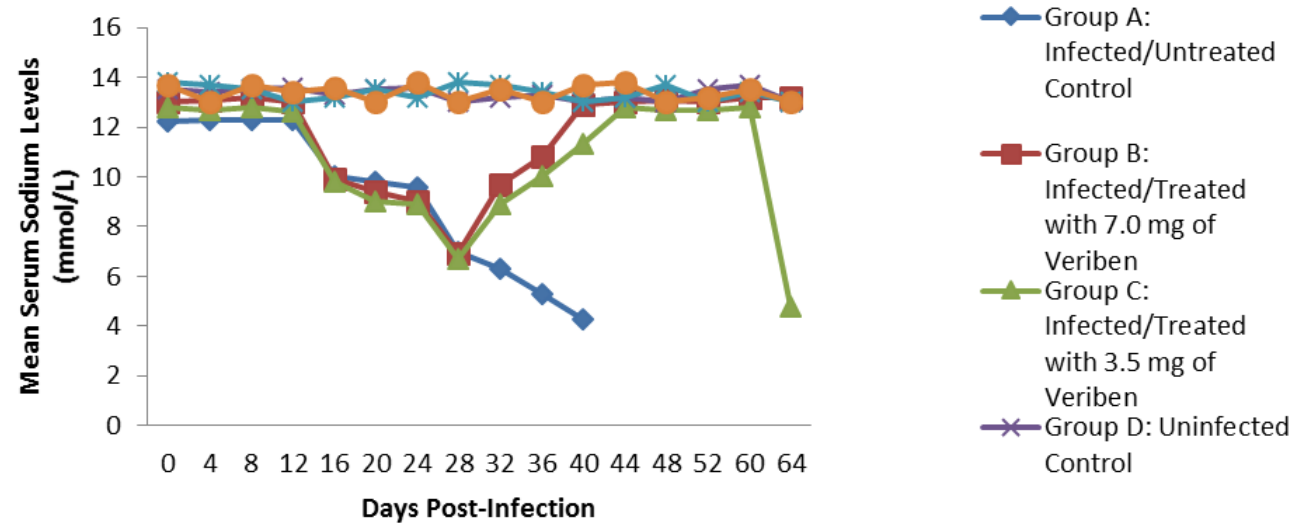

Figure 15 Effect of diminazene diaceturate (Veriben $®$ ) on the mean serum sodium levels (mmol/L) of Guinea pigs (C. porcellus) experimentally infected with T. brucei brucei and their controls

The mean serum calcium ion concentration, mean serum potassium levels and magnesium ion concentration of Guinea pigs (C.porcellus) experimentally infected with T.brucei brucei were continually decreased following establishment of parasitaemia by day 16 post infection in all the treated groups at different days interval as presented in (Fig 16, 17 and 18)
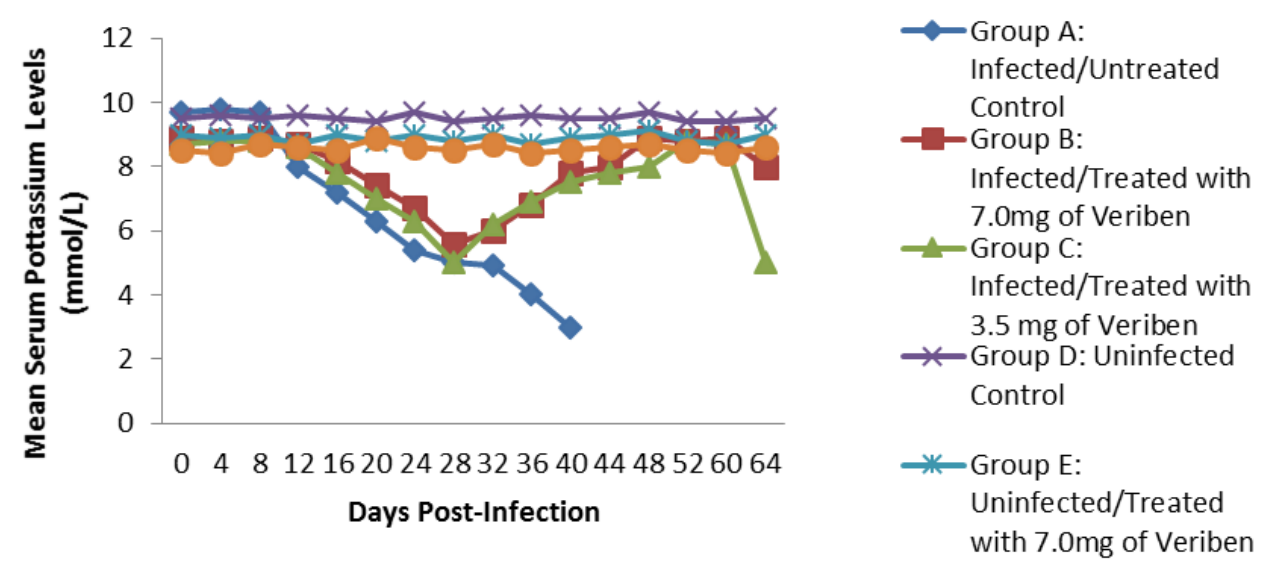

Figure 16 Effect of diminazene diaceturate (Veriben ${ }^{\circledR}$ ) on the mean serum pottassium levels (mmol/L) of Guinea pigs (C. porcellus) experimentally infected with T. brucei brucei and their controls 

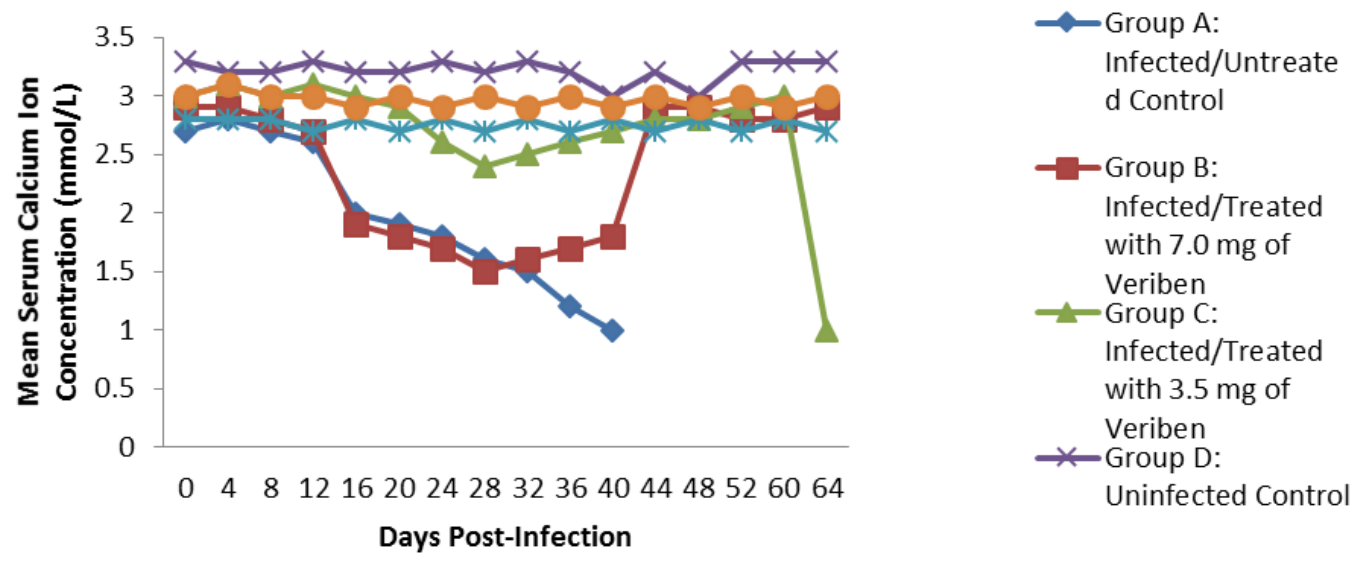

Figure 17 Effect of diminazene diaceturate $\left(\operatorname{Veriben}^{\circledR}\right)$ on the mean serum calcium ion conentrations (mmol/L) of Guinea pigs (C. porcellus) experimentally infected with T. brucei brucei and their controls
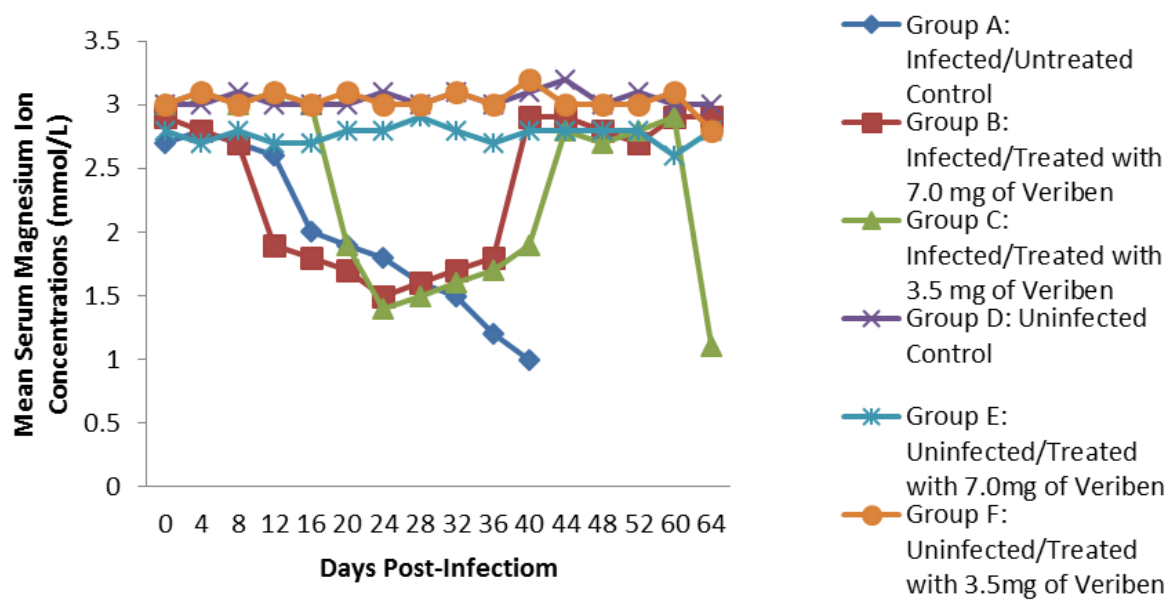

Figure 18 Effect of diminazene diaceturate $\left(\right.$ Veriben $\left.^{\circledR}\right)$ on the mean serum magnesium ion conentrations (mmol/L) of Guinea pigs (C. porcellus) experimentally infected with T. brucei brucei and their control

\section{Discussion}

The main clinical signs observed following experimental infection were respiratory distress, anemia, raised hair coat, dullness, anorexia and emaciation, this agreed with findings of several author reported in several species of laboratory animals and livestock. After the manifestation of clinical signs, the infected Guinea pigs shows parasitaemia by day 16 post infection. This is contrary to the findings of Umar et al [16] who observed a prepatent period of 4 days in rats infected with Trypanosoma brucei brucei. Infected Guinea pigs, started losing weight two weeks post infection. This may be associated with anorexia observed earlier, this was similar to the findings reported by Krinstensson et al [17] and Nyakundi et al [18] in rats infected with T. brucei brucei and rats infected with T. brucei gambiense [19] and also similar findings in rabbits infected with T. brucei brucei [20].

Despite the sudden changed in red cell parameters by decreased values of (PCV, RBC, Hb) during bouts of parasitaemia but gradually increased during the period of low and no parasitaemia. This tallies with the report of Yusuf et al. [21] who observed a significant decrease in PCV, Hb, RBC and platelet count in rats infected with T. b. brucei. This showed an inverse relationship between parasitaemia and anaemia in most of the infected animals [22,23]. Anaemia is a consistent feature of trypanosome infections associated by oxidative stress that inflict damage to erythrocytes membrane and associate components. Equally, reactive oxygen radicals generated during trypanosomosis can attack erythrocyte membranes, which may induces oxidative stress that can trigger haemolysis [24]. It was also observed in the current study that only the group of Guinea pigs infected with $T$. b. brucei and treated with $3.5 \mathrm{mg} / \mathrm{kg}$ diaminazene diaceturate (Veriben ${ }^{\circledR}$ ) developed relapse parasitaemia at day 36 post treatment. Relapse in trypanosomosis has been linked to the parasites moving into areas of the body that are not accessible to the drugs like the brain [25]. If infection is allowed to 
continue for some time before treatment then it is extremely difficult to obtain a permanent cure [25, 26, and 27]. Also Waitumbi et al. [26] reported relapse parasitaemia in rabbit infected with T.brucei brucei following treatment with 25 $\mathrm{mg} / \mathrm{kg}$ of diaminazene diaceturate. The difference with the current study in the occurred relapse might be attributed to difference species of animal used and the drug dosage. The haematological results of the present study agreed with earlier studies reported by [28, 11 and 29]. The low PCV observed in the infected group may be linked to acute hemolysis that occur due to the progressive nature of the infection. Previous studies have shown that infection with trypanosomes resulted in increased susceptibility of red blood cell membrane to oxidative damage probably due to depletion or reduction of glutathione on the surface of the red blood cell [11, 30, 31 and 32]. Severity of anaemia has been related to reflect the intensity and length of parasitaemia. Several reports [33, 34, 29 and 35] have also ascribed acute anaemia in trypanosomosis to proliferating parasites. The low leucocytes (WBC, lymphocytes, and neutrophils) and platelet counts observed in the infected group may be attributed to the immunosuppressive actions of trypanosome infection [36, 37]. The major function of platelets is to activate blood clotting mechanism and prevent loss of blood [29]. In this study, the low platelet count observed in the infected untreated groups may indicate destruction of platelets by toxic products emanating from the trypanosomes [38]. Low platelet counts may also be attributed to other factors like pooling of blood into the spleen, removal of platelets by mononuclear phagocytic system and increased consumption of platelets by disseminated intravascular coagulation reaction in trypanosome infection [39]. However, leukocytosis, lymphopaenia and neutrophilia reported, may be due to trypanosomosis and these conditions usually occur as a result of wear and tear syndrome associated with animal immune system caused by the ever changing in variable surface glycoprotein of the infecting trypanosomes [36]. The lymphopaenia encountered among the infected Guinea pigs may probably be due to an increased demand on the system for lymphocytes, which is a common requirement in both immune and inflammatory responses in trypanosomosis [11]. Inefficient recovery of iron from phagocytized RBCs is known to cause iron deficiency in the body [39]. Igbokwe [40] and Mbaya et al., [41] reported that dyserythropoiesis is associated with animal trypanosomosis, and this may be attributed to the decreased MCV that was observed in the present study among the infected untreated groups.

The T. brucei brucei infected Guinea pigs were observed to be associated with marked reduction in serum sodium and chloride ion levels, and this might have been due to renal tubular damage of the kidneys.

The decreased level of serum potassium observed in the current study was probably due to dehydration associated with tissue hypoxia [15]. Reduction in bicarbonate ion ( $\mathrm{HC}_{03}$-) levels may be probably due to acidosis. The reduction may also be due to decreased alveolar ventilation and tissues hypoxia similar findings was reported by Ogunsanmi et al., [42] in sheep infected by trypanosome.

The low bicarbonate levels can also be attributed to the massive leakages of some electrolytes from cells and tissues damage. However, the intermittent increase, low level and subsequent return of these electrolytes to pre-infection levels suggest the efficacy of the therapies, otherwise it might be as a result of massive cell and tissue damage at the terminal phase of this single infection. The decrease in the levels of calcium that was observed in this study agrees with the findings reported in cattle infected with T. congolense [43] and sheep infected with T. brucei brucei [42]. This is said to be due to the deficiency in the parathyroid hormone as a consequence of the destruction of the parathyroid glands or a decrease in serum carriers, which in this case happens to be albumin. The drop in the level of serum magnesium concentration noted among the T. brucei brucei infected Guinea pigs observed in this study does not tally with the findings of Sow et al. [44] among donkeys in Burkina Faso and that of Chaudhary and Iqbal [45] among camels in Pakistan. This may be as a result of the difference in the species of animals used. The drop in magnesium concentration in blood observed in this study might be due to lowered dietary intake due to the infections. Biochemical evaluation of the body fluids gives an indication of the functional state of the various body organs and biochemical changes in body fluids that result from infections depend on the species of the parasite and its virulence [46].

\section{Conclusion}

It is clearly understood the observed clinical signs among the infected groups (A, B and C) were pyrexia, pale feet, snout, pinnae and mucous membrane, anaemia, dullness, emaciation and loss of weight. In group A, a mean parasitaemia of $2.8 \pm 0.84$ occurred by day 16 post-infection post infection which continued to rise significantly without abating $(\mathrm{p}<0.05)$ to a peak count of $120.2 \pm 5.48$ by day 40 post infection. Which is absent in non-infected groups and that dose

of Veriben ${ }^{\circledR}$ administered at the dose rate of $7.0 \mathrm{mg} / \mathrm{kg}$ and $3.5 \mathrm{mg} / \mathrm{kg}$ have the abilities of curbing the state of anaemia, immunosuppression, and serum electrolytes levels in trypanosome-infected guinea pigs placed on a dose dependent manner. 


\section{Compliance with ethical standards}

\section{Acknowledgments}

The team of authors acknowledged the contribution of department of veterinary medicine, faculty of veterinary medicine and ethical department on animal welfare university of Maiduguri for the success of this research.

\section{Disclosure of conflict of interest}

All the authors agreed on the content of the manuscript. There is no any conflict of interest exist.

\section{Statement of ethical approval}

Ethical committee on animal Welfare University of Maiduguri, Borno State, Nigeria has given a full approval to go ahead with the research.

\section{References}

[1] Swallow BM. (2000). Impacts of trypanosomosis in African agriculture, programme against African trypanosomosis technical and scientific series. Food and Agricultural Organization (FAO), 2(45 - 46), 1020-7163.

[2] Codjia V, Mulatu W, Majiwa PAO, Leak SGA, Rowlands GJ and Authié E. (1993). Southwest Ethiopia Part 3. Occurrence of populations of $T$. congolense resistant to diminazene, isometamidium and homidium. Acta Tropica, $53,151-163$

[3] Taylor, MA, Coop RL and Wall RL. (2007).Veterinary Parasitology. Third Edn. Blackwell Publishing.

[4] Itty P. (1992). Economics of village cattle production in tsetse affected areas of Africa, A study of trypanosomosis control using trypanotorelant cattle and chemotherapy in Ethiopia, Kenya, Cote De Ivory, The Gambia, Zaire and Togo, Hurtong, Correvertag, Iconstanz (Germany).

[5] Soulsby EJL. (1982). Helminthes, Arthropods and Protozoa parasites of domesticated Animals, Bailere Tindal, ISBN 07020082069780702008207 , London

[6] Ngulde SI, Tijjani MB, Ihopo JM and Yauba, AM. (2013). Antitrypanasomal potency of methanol extract of Cassia arereh delile root back in albino rats. International journal of Drug Research and technology, 3, 1-7.

[7] Kettle DS. (1995). Medical and Veterinary entomology, $2^{\text {nd }}$ edition. CADI, Wallingford, 225-227.

[8] Ogwu D, Njoku CO and Ogbogu VC. (1992). Adrenal and thyroid dysfunction in experimental Trypanosoma congolense infection in cattle. Veterinary Parasitology, 42(15-26), 0304-4017

[9] Mbaya AW, Ibrahim UI and Apagu ST. (2010). Trypanosomosis of the dromedary camel (Camelus dromedarius) and its vectors in the tsetse-free arid zone of northeastern, Nigeria. Nigerian Veterinary Journal, 31(3), 195-200. ISSN 0331-3026

[10] Solano P, Dela Roqoes S and Duvalet G. (2003). Biodiversity of trypanosomes pathogenic for cattle and their epidemiological importance. Annals of Society, 68, $169-171$.

[11] Igbokwe IO. (1994). Mechanisms of cellular injury in African trypanosomiasis, Veterinary Bulletin, 64(7), 611620.

[12] Mbaya AW and Ibrahim UI. (2011). In-vivo and in-vitro activities of medicinal plants on haemic and humoral trypanosomes: A review, International Journal of Pharmacology, 7(1), 1- 11. ISSN 1812-5700.

[13] Herbert WJ and Lumsden WHR. (1976). Tryponosoma brucei: A rapid matching method for estimating the host's parasitaemia. Journal of Experimental Parasitology, 40, 427-432.

[14] Henry R, Cannon DC and Winkelman JW. (1974). Clinical Chemistry: Principle and Technics. Hagerstown, M. D Harper and Row London, 543.

[15] Tietz NW. (1994). Serum albumin determination. Fundamentals of clinical chemistry with clinical Correlation. Balliere Tindall, London, UK, 2334 
[16] Umar IA, Ogenyi E, Okodaso D, Kimeng E, Stancheva GI, Omage JJ, Isah, S and Ibrahim M. A. (2007). Amelioration of anaemia and organ damage by combined intraperitoneal administration of vitamins A and C to Trypanosoma brucei brucei -infected rats. African Journal of Biotechnology, 6, 2083.

[17] Kristensson K, Claustrat B, Mhlanga JDM and Moller M. (1998). African trypanosomiasis in the rat alters melatonin secretion and melatonin receptor binding in the suprachiasmatic nucleus. Brain Research Bulletin, 47, 265-269.

[18] Nyakundi JN, Crawley B, Smith RA and Pentreath VW. (2002). The relationships between intestinal damage and circulating endotoxins in experimental Trypanosoma brucei brucei infections. Parasitology, 124, 589-595.

[19] Nishimura K, Araki N, Ohnishi Y and Kozaki S. (2001). Effects of dietary polyamine deficiency on Trypanosoma gambiense infection in rats. Experimental Parasitology, 97, 95-101.

[20] Toth, L. A., Tolley, E. A., Broady, R., Blakely, B. and Krueger, J.M. (1994). Sleep during experimental trypanosomiasis in rabbits. Proceedings of Society for Experimental Biology and Medicine, 205, 174-181.

[21] Yusuf OS, Oseni BS, Olayanju AO, Hassan MA, Ademosun AA and Akele RY. (2013). Acute and chronic effects of Trypanosoma brucei brucei experimental infection on bone marrow and peripheral blood cells in wistar rats. Scholars Journal of Applied Medical Sciences, 1(6), 1036-1040.

[22] Nwosu CO and Ikeme MM. (1992). Parasitaemia and clinical manifestations in Trypanosoma brucei brucei infected dogs. Revenue d'Elevage: et de Medicine Veterinaire des pays Tropicaux, 45, 273-277.

[23] Mbaya AW, Aliyu MM, Nwosu CO and Egbe-Nwiyi, TNC. (2009c). The relationship between parasitaemia and anaemia in a concurrent Trypanosoma brucei and Haemonchus contortus infection in red fronted gazelles ( Gazella rufifrons) .Veterinarski Arhive 76(5), 451-460

[24] Ngure RM, Ongeri B, Karori MS, Wachira W, Maathai RG, Kibugin JK, and Wachira FN. (2009). Anti-trypanosomal effects of Azadiracta Indica (neen) extract on trypanosomes Brucei rhodesiense Injected Mice. Eastern Journal of Medicine 14, 2-9.

[25] Jenning FW and Gray GD. (1982). Relapse of Monomorphic and Pleomorphic Trypanosoma brucei infection in the mouse after chemotheraphy, Z parasitenkd, 67(2),137-45

[26] Waitumbi JN, Brown HC, Jennings FW and Holmes PH. (1988). The relapse of Trypanosoma brucei brucei infections after chemotherapy in rabbits. Acta Tropica, 45(1), 45-54.

[27] Mbaya AW, Kumshe HA, Nwosu CO and Onyeyili PA. (2007). Toxicity and anti trypanosomal effect of Butyrospermum paradoxum (Sapotaceae) stem bark in rats infected with Trypanosoma brucei and Trypanosoma congolense. Journal of Ethnopharmacoloy, 111, 526-530.

[28] Anosa VO. (1988). Haematological and biochemical changes in human and animal trypanosomosis II. Revue d'élevage et de médecine vétérinaire des pays tropicaux, 41(1), 65-78.

[29] Ekanem JT, Kolawole OM, Abbah OC. (2008). Trypanocidal potential of methanolic extract of Bridelia ferruginea benth bark in Rattus novergicus. African Journal of Biochemistry Research 2(2), 045-050

[30] Igbokwe IO, Umar IA, Omage JJ, Ibrahim NDG, Kadima KB, Obagaiye OK, Saror DI and Esievo KAN. (1996). Effect of acute Trypanosoma vivax infection on cattle erythrocyte glutathione and susceptibility to in vitro peroxidation. Veterinary Parasitology, 63, 215-24.

[31] Taiwo VO, Olaniyi MO and Ogunsanmi AO. (2003). Comparative plasma biochemical changes and susceptibility of erythrocytes to in vitro peroxidation during experimental Trypanosoma congolense and Trypanosoma brucei infections in sheep. Israel Journal of Veterinary Medicine, 58(4), 435-443.

[32] Akanji MA, Adeyemi OS, Oguntoye SO and Sulyman F. (2009). Psidium guajava extract reduces trypanosomiasis associated lipid peroxidation and raises glutathione concentration in infected animals. Experimental and clinical science Journal, 8, 148-154.

[33] Ogunsanmi AO and Taiwo VO. (2001). Pathobiochemical mechanisms involved in the control of the disease caused by Trypanosoma congolense in African grey duiker (Sylvicapra grimmia). Veterinary Parasitology, 96, 5163.

[34] Umar IA, Ogenyi E, Okodaso, D, Kimeng E, Stancheva GI, Omage JJ, Isah, S and Ibrahim MA. (2007). Amelioration of anaemia and organ damage by combined intraperitoneal administration of vitamins A and C to trypanosoma brucei brucei infected rats, Academic Journals, 6(18), 2083-2086. 
[35] Saleh MA, Bassam MA and Sanousi SA. (2009). Oxidative stress in blood of camels (camelus dromedaries) naturally infected with Trypanosoma evansi. Veterinary parasitology. 162, 192-9.

[36] Abubakar A, Iliyasu B, Yusuf AB, Igweh AC and Onyekwelu NA. (2005). Antitrypanosomal and haematological effects of selected Nigerian medicinal plants in Wistar rats. Biokemistri journal. 17, 95-99.

[37] Ekanem JT and Yusuf OK. (2008). Some biochemical and haematological effects of black seed (Nigella sativa) oil on Trypanosoma. brucei-infected rats. African Journal of Biomedical Research 11, 79 - 85

[38] Dow RB. (1994). The clinical and laboratory utility of platelet volume parameters. Australian journal of Medical Science, 15, 1-8.

[39] Kagira JM, Thuita JK, Ngotho M, Mdachi, R and Mwangangi, DM. (2006) Haematology of experimental Trypanosoma brucei rhodesiense infection in vervet monkeys. African Journal of Health Sciences, 13, 59-65.

[40] Igbokwe IO and Nwosu CO. (1997). Lack of correlation of anaemia with splenomegaly and hepatomegaly in Trypanosoma brucei brucei and Trypanosoma congolense infections of rats. Journal of Complex Pathology. 117, 261-5.

[41] Mbaya AW, Kumshe HA, and Nwosu CO. (2012). The mechanism of anaemia in Trypanosomosis (D.S. Silverberg Ed.), In Tech. Publishers, Croatia, 240-282.

[42] Ogunsanmi AO, Akpavieso PA and Anosa VO. (1994). Serum Biochemical changes in WAD Sheep experimentally infected with Trypanosoma brucei, Tropical Veterinarian, 47(2), 195.

[43] Fiennes RN, Jones RE and Laws SG. (1946): The course and pathology of T. congolense (Broden) desease of cattle. Journal of Comparative Pathology, 46, 1-27

[44] Sow A, Zabré MZ, Mouiche MMM, Kouamo J, Kalandi M, Bathily A, Sawadogo GJ and Ouédraogo GA. (2014). Investigation of Biochemical Parameters in Burkinabese Local Small Ruminants Breed Naturally Infected with Trypanosomosis. International Journal of Biochemistry Research \& Review, 4 (6), 666-679.

[45] Chaudhary ZI and Iqbal J. (2000). Incidence, biochemical and haematological alterations induced by natural trypanosomosis in racing dromedary camels. Acta Tropica, 77, 209-213.

[46] Awobode HO. (2006). The biochemical changes induced by natural human African trypanosome infections. African journal of biochemistry, 5(9), 738-742.

\section{How to cite this article}

Abdullahi AM, Iliyasu D, Galadima HB, Ibrahim UI, Mbaya AW and Wiam I. (2019). Effects of trypanosomosis on hemogram and some biochemical parameters of guinea pigs experimentally infected with Trypanosoma brucei brucei in Maiduguri, Nigeria. GSC Biological and Pharmaceutical Sciences, 7(1), 62-74. 